\title{
Cultura Cultura
}

vol. 38 | 2019

Bibliotecas públicas, políticas culturais e leitura pública

a polissemia de um conceito e suas práticas

\section{As bibliotecas sem muros}

a polissemia de um conceito e suas práticas

\section{Débora Dias}

\section{(2) OpenEdition}

1 Journals

\section{Edição electrónica}

URL: https://journals.openedition.org/cultura/5474

DOI: $10.4000 /$ cultura. 5474

ISSN: 2183-2021

\section{Editora}

CHAM - Centro de Humanidades

\section{Edição impressa}

Data de publição: 31 dezembro 2019

ISSN: 0870-4546

\section{Refêrencia eletrónica}

Débora Dias, «As bibliotecas sem muros», Cultura [Online], vol. 38 | 2019, posto online no dia 02 janeiro 2021, consultado o 25 julho 2021. URL: http://journals.openedition.org/cultura/5474 ; DOI: https:// doi.org/10.4000/cultura.5474

Este documento foi criado de forma automática no dia 25 julho 2021.

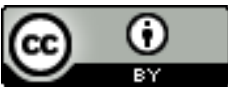

Cultura is licensed under a Creative Commons Atribuição 4.0 International. 


\title{
As bibliotecas sem muros
}

\author{
a polissemia de um conceito e suas práticas
}

\section{Débora Dias}

1 Pensando-a como "lugar", reunião de livros e projeto, Christian Jacob afirma que "toda biblioteca dissimula uma conceção implícita de cultura, do saber e da memória, bem como da função que lhes cabe na sociedade de seu tempo" (Jacob 2000, 10), com a ressalva de que a subversão dessas regras, desses limites, bem como a invenção de novas ligações e lugares de saber sejam uma constante na história da cultura e da relação com a memória.

2 Dito isso, compreende-se que o desenvolvimento do conceito de bibliotecas esteja associado às dinâmicas contextuais e históricas que incluem também a materialidade dos suportes de informação: das placas de argila aos papiros, dos códices em pergaminhos aos incunábulos em papel de trapo, dos impressos em celulose às interfaces analógicas ou digitais. Frente a um conceito que se alargou, e cuja compreensão não pode dispensar a sua historicidade, interessa aqui levantar os diferentes significados do termo "bibliotecas sem muros" (ou, a depender da tradução, "bibliotecas sem paredes"), bem como seus usos e intencionalidades em distintos territórios e temporalidades. Especialmente a partir de casos iberoamericanos, discutem-se alguns exemplos demonstrativos em que o "como se lê" e o "o que se lê" podem fundar ou alterar os próprios projetos de bibliotecas.

\section{As bibliotecas sem muros}

4 A ideia de "depósito de livros" está na origem da palavra: a versão latinizada Bibliotheca origina-se do grego Biblion, que significa "livro", e Theke, "depósito" ou "caixa". Também usada como a "estante" onde estão os papiros, como interpretou Luciano Canfora no uso da palavra em textos da Antiguidade (Canfora 1989, 77). Nessa etimologia está a chave de outras aceções do termo que chega ao século XXI acumulando semânticas distintas: é um conjunto sistematizado de livros com determinados fins de utilidade pública ou particular e propósitos de formação intelectual nas diferentes áreas do conhecimento (Carlo 1971, 227), como também é a designação para um tipo de móvel, um armarium, ou para uma dependência (Faria e 
Pericão 2008,147$)^{1}$ ou edifício destinado a abrigar coleções de livros e documentos, "devidamente ordenadas, para consulta pública ou particular"; é ainda sinônimo de "centro de recursos de informação e ideias" ou de ensino, assim como, em informática, é "um conjunto organizado de ficheiros que são colocados à disposição dos utilizadores" (Faria e Pericão 2008, 147-148).

5 Para Sayão, tais perspectivas estariam superadas quando se trata de bibliotecas digitais (Sayão 2008-2009, 6-17)2. O autor compartilha da definição de Paul Duguid de bibliotecas digitais como "ambiente distribuído que integra coleções, serviços e pessoas na sustentação do ciclo de vida completo de criação, disseminação, uso e preservação de dados, informação e conhecimento" (Duguid apud Sayão 2008-2009, 9).

6 Sem desenvolver essa discussão, para o caso aqui tratado, interessa assinalar que a definição de biblioteca digital inclui de modo recorrente o termo "biblioteca sem paredes" como sinônimo. A ideia é conhecida: a tecnologia digital seria capaz de ultrapassar os limites físicos de acumulação de títulos e acesso a obras, agregando potencialidades que construiriam a "biblioteca do futuro", pelo menos segundo concepções (reais ou imaginadas) vistas desde meados do século XX (Drabenstott e Burman 1994, 4). Nessa filiação, o Dicionário do Livro traz o termo "biblioteca sem paredes" com o único significado de "biblioteca electrónica, biblioteca virtual" (Faria e Pericão 2008, 156), o que não deixa de aludir à materialidade do suporte.

7 É de notar que a definição de "biblioteca sem paredes" chega ao século XXI com um propósito compartilhado desde as origens do termo, que remonta ao século XVI, em torno do mito da universalidade. Também aqui é a biblioteca como o lugar que comporta o sonho do Ocidente de reunir todo o conhecimento do mundo. Esta aspiração é vista em catálogos, mesmo antes de 1550, que se propunham a reunir todos os livros publicados, quer por um território, quer por toda humanidade, como foi o caso da Bibliotheca Universalis (Zurique, 1945), de Conrad Gesner (1516-1565). Chamado de "pai da bibliografia", Gesner inovou ao substituir a palavra catálogo por uma nova utilização de bibliotheca, "que liberta a palavra da sua definição material e atribui à biblioteca sem paredes, proposta pelo livro, o sinal do universal” (Chartier 1997, 109).

8 Para o caso português, importa referir a Biblioteca Lusitana (Machado 1741-1759), a primeira grande bibliografia em língua portuguesa. Escrita por Diogo Barbosa Machado e impressa por António Isidoro da Fonseca, buscou reunir toda notícia dos autores portugueses e das obras que se compuseram até então. Foi predecessora de outras obras do gênero, incluindo aquela que seria uma referência sobre obras publicadas em Portugal até o fim do século XIX, o Dicionário Bibliográfico Português, iniciado por Inocêncio Francisco da Silva em 1858.

Por essa chave, chegamos ao significado da biblioteca como Livro. É a biblioteca como "uma compilação de várias obras do mesmo gênero, ou de autores que compilam tudo que pode ser dito acerca do mesmo tema" (Chartier 1997, 101), designação que Roger Chartier localiza desde o século XVII (caso do Dictionnaire de Furetière, de 1690). Assim, de um lugar (edifício, galeria, estante), biblioteca passa a também nomear um gênero editorial: é uma tipologia de livro ou coleção, significado que se mantém até os dias de hoje como uma "seleção, compilação de diversas obras da mesma natureza ou de autores que compilaram tudo quanto pode dizer-se acerca de um mesmo tema", mas também coleção em vários volumes, "que reúne uma grande quantidade de obras já publicadas de um determinado género" (Faria e Pericão 2008, 148). Essas são também as 
"bibliotecas sem muros", na expressão usada por Roger Chartier para referenciar os livros e as coleções e compilações dos séculos XVII e XVIII ${ }^{3}$ (Chartier 1997).

O sentido do termo assim usado é duplo, pois, sendo um livro, é também a coleção de que o livro dá conta. É uma coleção verdadeira nos critérios que a constituem, e imaginada porque impossível de reunir fisicamente.

11 Compartilhando dessa aceção, as coleções temáticas também se constituem como "bibliotecas sem paredes", exemplo da Brasiliana, da Camoniana, da Machadiana, da Judaica, entre outras. Isto é, mantém-se sem muros como concepção ideal para o bibliófilo, que constrói virtualmente sua biblioteca, enquanto almeja e tenta transformá-la numa biblioteca física, cerrada em muros, à medida em que adquire os livros.

12 De todas essas definições de bibliotecas, dois sentidos imperam e não se excluem: a biblioteca como coleção e como ambiente (de informação, de cultura, de educação) e a biblioteca como projeto. E se a biblioteca é por vocação totalizadora, mesmo quando se especializa, pois está sob o imperativo de reunir, não tudo, mas o todo mutável daquilo que importa, sempre importará saber quem ou o que preside a esta organização, classificação e hierarquização do saber ou obra que ela visa guardar, e qual o destino dos conhecimentos que acumula.

\section{A coleção como biblioteca}

Assim também será em relação às coleções que formam "bibliotecas sem paredes" e que desempenham um papel significativo na revolução editorial no século XIX. É o momento em que surge a figura do editor contemporâneo, que pensa pequenas bibliotecas virtuais, com um plano editorial estruturado, com vistas a serem bibliotecas concretas, com livros produzidos que serão colecionáveis.

Com formato menor, redução de preço e modos característicos de apresentação dos volumes, Isabelle Olivero localiza na Bibliothèque Charpentier (1838) o prenúncio do desenvolvimento de coleções que chegam às modernas versões de bolso dos nossos dias (Olivero 1999). As estratégias implementadas pelas casas editoras e a seleção dos textos ou obras para entrar nas coleções acompanham o duplo objetivo: ampliar o número de leitores e, desse modo, garantir muitas vezes a existência da própria casa editora, e igualmente responder a uma demanda que depositava no livro a missão de educar, civilizar, universalizar (Carvalho e Toledo 2003).

Resguardadas as diferenças nos processos europeus e latino-americanos, pode-se afirmar que o livro se tornou objeto de consumo da sociedade oitocentista, além de veículo de circulação de ideias, comunicação e mensagem. A constituição de um mercado industrial do impresso, a concorrência entre editores, a emergência de novos leitores, os avanços nas técnicas de impressão (favorecendo edições em maior escala e com menores preços), o aumento do acesso das classes médias aos bens culturais, a necessária educação das classes laboriosas, a reorganização de meios e formas de educação e de cultura, a ampliação da alfabetização e liberalização legislativa da imprensa são elementos conjunturais, estruturais e inter-relacionados para a formação desse cenário também para a sociedade portuguesa (Ribeiro 1999, 188).

Livros diferentes passam a ser editados para categorias de leitores diferentes: mulheres, estudantes, religiosos, crianças, viajantes, comerciantes, profissionais. E passam também a ter usos distintos, transitando do mundo público ao privado, constituindo bibliotecas familiares, voltados para a organização da vida doméstica, para leituras 
compartilhadas ou momentos de lazer, incluindo decisivamente as mulheres nas tensões entre o livro proibido e o aconselhável (Vaquinhas 2010, 89). Esse alargamento do público leitor passava inevitavelmente por tornar mais barato o acesso à leitura.

Nesse sentido, edições voltadas para o entretenimento ou vulgarização do conhecimento científico proliferaram, e outros critérios passaram a vigorar nesse campo onde a competição entre livreiros e editores valorizava mais o conjunto do que a obra rara. Na afirmação de Jean-Yves Mollier, o século XIX foi o século dos dicionários e também das coleções e enciclopédias (Mollier 2008). Integram as novas estratégias editoriais, novas formas de organização, apresentação e até mesmo reprodução de textos acessíveis a um número maior de leitores.

Os chamados "novos leitores", em busca de instrução e fruição pela leitura, são o público a ser alcançado pelas coleções e estas não deixaram de explorar o prestígio que o uso do título "Biblioteca" já gozava no seio de camadas menos eruditas. $\mathrm{O}$ formato aparece como opção privilegiada para estabelecer vínculos e participar da formação de leitores, quer com a edição e organização de almanaques, quer com o lançamento de obras em fascículos por assinatura ${ }^{5}$, quer ainda com a edição de coleções de livros que perpassam décadas e tornam-se conhecidas de diferentes gerações. Estudos de Manuela Domingos apontam nesse sentido a partir da análise da Biblioteca do Povo e das Escolas, coleção da Casa Editora David Corrazzi em Lisboa (Domingos 1985), estudada ainda no seu amplo alcance pelo Brasil (Martins 2005), por exemplo.

\section{Leitores e outros projetos de "bibliotecas sem muros"}

Destaque-se um duplo movimento. Por um lado, dá-se a adesão de letrados reconhecidos, intelectuais e escritores, nos seus diferentes modos e perfis, a esses projetos de alargamento e formação do público leitor nas suas variantes literária e científica ${ }^{6}$. Para o século XIX português, citem-se nomes como os irmãos António e José Feliciano de Castilho, com a coleção Livraria Clássica Portuguesa, e Eça de Queiroz como organizador do Almanaque Enciclopédico para 1896 e 1897, entre muitos outros ${ }^{7}$. Compreende-se que tais projetos carregam a intenção de extrapolar da biblioteca do erudito o conhecimento classificado e selecionado, difundindo a ideia de "biblioteca sem muros" desenvolvida desde o século XVII.

São muitas as coleções e mesmo as empresas que usam a palavra "Biblioteca" nos seus nomes, umas vezes restringindo o seu âmbito, outras alargando-o. Temos, assim, entre outras, a Biblioteca Económica, a Biblioteca Romântica, a Biblioteca Histórica, a Biblioteca Horas de Recreio, a Biblioteca do Carroção, onde Camilo Castelo Branco chegou a publicar8, a Biblioteca Franco-Lusa, a Biblioteca Lisbonense, a par da Biblioteca Clássica e da Biblioteca Universal, nominalmente mais ambiciosas. São bibliotecas virtuais nos projetos de editores, desejando que elas se tornassem bibliotecas físicas nas casas de cada um.

É nos próprios livros que fica explícita essa articulação. Com o evocativo título Bibliotheca Universal Antiga e Moderna, a coleção lançada pela Casa Editora David Corazzi, em 1888, anuncia em prefácio o empenho em conseguir chegar "às mãos de todos, constituindo em todas as famílias e em todas as corporações associativas uma encyclopedia consoladora". Isso porque "apenas um ou outro erudito" teria as condições para ler as obras-primas, frutos da "intelligencia, do genio ou do saber" de autores afamados. Enquanto para uns é dispendioso reunir tantos volumes e formar uma biblioteca com as obras em original, para outros a barreira está na "impossível compreensão da enorme diversidade de línguas", referindo a ausência de traduções, ou 
ainda a falta de tempo para se ler tão "extensos e numerosissimos volumes de cada autor" (Prefácio 1888, 4).

A solução apresentada pela coleção Bibliotheca Universal Antiga e Moderna é publicar de cada autor "o mais selecto", "o indispensável a ser conhecido", combinando leitura abundante, formato portátil, "barateza inexcedível" e obras "menos volumosas e mais amenas". A seleção dos títulos tem em conta ainda "o gosto literário e a aptidão scientifica do escriptor que a dirige". Isso porque a coleção leva a chancela (e em alguns casos o trabalho de tradução) do escritor, crítico, jurista ou poeta que a organiza, responsável ainda por pequenas biografias dos autores selecionados. Exemplos são o poeta António Gomes Leal, o jurista e político Fernandes Costa, a escritora Mécia Mouzinho de Albuquerque (que assina Mência), para citar somente alguns.

Também justificado por preocupações educativas, no caso em relação à classe média e ao ensino secundário, nos finais da década de 1870, o historiador Oliveira Martins lançou o projeto de uma "Biblioteca das Ciências Sociais", de caráter não erudito e voltada a um público mais amplo. Mas, ao contrário de outros exemplos citados, não buscou fazer uma compilação de obras ou de autores, pois propunha-se escrever todos os livros dessa biblioteca enciclopédica. Na divulgação do plano de volumes, como na análise das obras finalmente publicadas, percebe-se que postulava uma ordenação epistêmica e uma ordem ideal de leitura do que iria publicar (Catroga 1996, 120).

Sabe-se que, em Portugal, sobretudo nos anos 1870 e 1880, estava na ordem do dia pensar o problema do conhecimento em termos de hierarquização das ciências. Auguste Comte foi o que maior impacto teve, quer pela difusão de seus preceitos, quer pelo fomento de polêmicas e divergências. E muito embora Oliveira Martins, que tinha como mestre Cournot, se definisse contra o positivismo e discordasse em muitos pontos da classificação comtiana das ciências, concordava com o preceito segundo o qual "todos os fenômenos observáveis eram passíveis de serem classificados num pequeno número de categorias naturais, dispostas numa série hierarquizada, em que o estudo de cada categoria se alicerçava no conhecimento das leis da categoria precedente, ao mesmo tempo em que passava a constituir a base para a ciência seguinte" (Catroga 1996, 120).

Nesse sentido, a Antropologia é indicada por Martins como "prólogo" da vasta obra de sua biblioteca, enquanto ciência social mais geral e menos complexa na sua taxonomia, muito embora a ordenação sugerida pelo autor não acompanhe a ordem cronológica de publicação dos títulos. Em sete anos, sob a epígrafe "Biblioteca de Ciências Sociais", sairiam os títulos: O Helenismo e a Civilização Cristã (1878), História da Civilização Ibérica (1879), História de Portugal (1879), Elementos de Antropologia (1880), O Brasil e as Colónias Portuguesas (1880), Portugal Contemporâneo (1881), As Raças Humanas e as Civilizações Primitivas (1881), Da Natureza e Lugar das Ciências Sociais (1881), Sistema dos Mitos Religiosos (1882), Quadro das Instituições Primitivas (1883), o Regime das Riquezas (1883), Tábuas de Cronologia e Geografia Histórica (1884), História da República Romana (1885). Vistos no conjunto, no entanto, pode-se captar o desenho de uma biblioteca enciclopédica em construção, que mobiliza livros, autores e leituras numa ordem formada por seu organizador e que não se encerra em si mesma.

\section{Bibliotecas ambulantes}

Na América Latina, a busca desse livro-biblioteca, que traria a chave do que se precisa para ler o mundo, é vista nas memórias de Domingo Faustino Sarmiento, como estudado por Graciela Batticuore. É o leitor que se formou a si mesmo numa casa sem 
bibliotecas, sem livros, numa província sem escolas e sem professores de prestígio. Ou, apresentando-se como um autodidata ao seu leitor, recordando com o "imaginário do desejo" (Batticuore 2016, 53-54). Assim, educou-se com os livros que buscava e rebuscava, entre amigos e conhecidos. Os "catecismos de Ackerman", de onde aprendeu sobre história, geografia, política e ideias, "graças a mediação daqueles bons europeus que pensaram como educar os americanos" (Batticuore 2016, 53).

Mas, para o caso aqui em questão, importa realçar que, para se "contar" leitor, em busca desses livros que valiam por bibliotecas porque traziam o que seria fundamental, Sarmiento conta do leitor que quer ser, contando aquilo que valoriza, mesmo que parte de uma estratégia de reconhecimento. Para Batticuore, Sarmiento era o escritor em busca de sua entrada nas bibliotecas nacionais argentinas, em plena formação no período romântico, como também nas bibliotecas europeias, alvo de qualquer americano dos séculos XIX, XX e XXI.

31 No rastro de Sarmiento e seus personagens, é longa a galeria de leitores, incluindo também escritores, que deambularam pelos pampas, indo e vindo de um lado a outro da fronteira. Para o caso argentino, Batticuore lista uma sequência de tipos: "los lenguaraces e intérpretes, los indios legos, alfabetizados, los viajeros y letrados que se internan tierra adentro munidos de libros y papeles, a veces incluso de una imprenta móvil" (Batticuore 2016, 58). Viajantes como Lucio Mansilla, escritor argentino do século XIX, que instala um escritório de campanha, com todos os recursos que possuía na cidade (incluindo dois escrivães), com o propósito de estender a divisa entre os territórios brancos e indígenas. $\mathrm{E}$ os exemplos dos índios leitores do século XIX amplia a galeria de leituras na fronteira, na vida real e na literatura. O próprio Mansilla surpreende a si e aos leitores do seu tempo em encontrar, na primeira parada terra adentro, o cacique Mariano Rosas, que não somente sabia ler e escrever, mas guardava um arquivo de jornais e recortes de jornais, fundamental para se proteger dos enganos e trapaças na hora de firmar tratados e alianças. Não se tratava de um caso excepcional, quando vários outros filhos de caciques eram enviados á cidade para se preparar melhor na defesa dos seus.

São imagens que remetem a bibliotecas em movimento, quer seja na escolha dos impressos e manuscritos que seriam fundamentais para as empreitadas $e$ deslocamentos, incluindo compilações, periódicos, textos técnicos ou religiosos, literatura, dicionários, mapas, como também na produção de novos escritos, diários, cartas, relatórios, cartografias. Não se trata apenas da comunicação entre interior e capital, ou das produções administrativas e burocráticas. Mas de uma gama de possibilidades mais vasta e até extrema. Nessa galeria, já no século XX, pode-se incluir a paradoxal cena do guerrilheiro em marcha que não abdica dos livros: Che Guevara, em meio a selva boliviana, lendo no alto de uma árvore, carregando livros junto ao corpo, escondendo uma pequena biblioteca junto a víveres em uma gruta (Piglia 2014, 97).

Ao perguntar "o que é um leitor?", Ricardo Piglia não deixa de mirar também o outro, quem busca ler aquele que lê, nas suas intenções e concepções. "La pregunta - a veces irónica, a veces agresiva, a veces piadosas, pero siempre política - del que mira leer al que lee" (Piglia 2014, 28). Pergunta que também embute a questão de como os livros vão parar nas mãos daquele que os lê. Nessa diversidade de encontro com os textos, o autor chama a atenção para os livros encontrados, emprestados, roubados, herdados, saqueados, salvos do naufrágio, que se distanciam e se perdem na planície (Piglia 2014, 30). Podemos ainda perceber como esse panorama de circulação da cultura põe em 
causa dicotomias como letrados e iletrados, alfabetização e analfabetismo, erudito e popular. Ou ainda na oposição civilização e barbárie, dualidade tão difundida pelos letrados latino-americanos, como o próprio Sarmiento. Para Batticuore, essa dicotomia resulta numa matriz de entrada na cultura argentina que a história da leitura e da autoria na América Latina pode ajudar a desmontar (Batticuore 2016, 63). regime autoritário, que torna todos os livros ilegais e os condena à fogueira, cada um dos oposicionistas decora o conteúdo inteiro de uma obra, antes de esta ser destruída. De modo a garantir a preservação e a transmissão dos saberes, surgem os "homenslivro", termo usado pelo autor. É sugestivo considerar que o conjunto desses homens e mulheres-livro também formaria novas bibliotecas sem paredes.

Num sentido inverso, há o chamado de preservação de "bibliotecas sem muros" sob o risco concreto de destruição de culturas ancestrais e orais. Por exemplo, os anciões de culturas tradicionais no Brasil - indígenas, ribeirinhos, quilombolas - são vistos como fontes de transmissão de ideias, da cultura, da história e da memória de um povo. Este pode ser um outro sentido de bibliotecas sem muros.

\section{BIBLIOGRAFIA}

Academia das Ciências de Lisboa. 2001. Dicionário da Língua Portuguesa Contemporânea. Lisboa: Academia das Ciências de Lisboa/Editorial Verbo. 
BATTICUORE, Graciela. 2016. "Biblioteca y lectores argentinos: escenas fundantes". In Escrita, edição e leitura na América Latina. Organizado por Nelson Schapochnik e Gisele Martins Venâncio, 49-65. Niterói: PPGHistória-UFF.

BERNARDO, Luís Miguel. 2013. Cultura Científica em Portugal. Uma perspetiva histórica. Porto: Universidade do Porto.

CANFORA, Luciano. 1989. The Vanished Library. Berkeley/Los Angeles: University of California Press.

CARLO, Agustín Millares. 1971. Introducción a la Historia del libro y de las bibliotecas. México: Fundo de Cultura Económica.

CARVALHO, Marta Maria Chagas de, e Maria Rita de Almeida Toledo. 2003. "A coleção como estratégia editorial de difusão de modelos pedagógicos: o caso da Biblioteca de Educação, organizada por Lourenço Filho". In Congresso Brasileiro de História da Educação, 3, Curitiba. Anais... Curitiba: SBHE.

CATROGA, Fernando. 1996. "História e ciências sociais em Oliveira Martins". In História da História em Portugal sécs. XIX-XX. Organizado por Luís Reis Torgal, José Maria Amado Mendes e Fernando Catroga, 117-159. Lisboa: Círculo de Leitores.

CHARTIER, Roger. 1997. A ordem dos livros. Tradução de Leonor Graça. Lisboa: Vega/Passagens.

DARNTON, Robert. 1992. "História da Leitura”. In Peter Burke (org.). A escrita da história. Tradução de Magda Lopes. São Paulo: Unesp.

DIAS, Débora. 2019. “A longa 'República das Letras' e o século dos intelectuais: notas para a história das bibliotecas no Ocidente”. Investigación Bibliotecológica: archivonomía, bibliotecología e información 33 (81): 157-178.

DOMINGOS, Manuela D. 1985. Estudos de sociologia da cultura. Livros e leitores do século XIX. Lisboa: Instituto Português de Ensino à Distância.

DUTRA, Eliana de Freitas. 2006. “A nação dos livros: a biblioteca ideal na coleção Brasiliana”. In Política, nação e edição. Organizado por Jean-Yves Mollier e Eliana de Freitas Dutra, 299-314. São Paulo: Annablume.

FARIA, Maria Isabel, e Maria da Graça Pericão. 2008. "Biblioteca”. In Dicionário do Livro. Da escrita ao livro electrónico, 147-148. Coimbra: Almedina.

JACOB, Christian. 2000. "Prefácio". In O poder das bibliotecas: a memória dos livros no Ocidente, 9-17. Dirigido por Marc Baratin e Christian Jacob. Tradução de Marcela Mortara. Rio de Janeiro: Ed. da UFRJ.

MACHADO, Diogo Barbosa. 1741-1759. Bibliotheca Lusitana historica, critica e cronologica na qual se comprehende a noticia dos Authores Portuguezes, e das Obras, que compuserão desde o tempo da promulgação da Ley da Graça até o tempo prezente: Offerecida à Augusta Magestade de D. João V nosso senhor (4 vol). Lisboa: António Isidoro da Fonseca.

MOLLIER, Jean-Yves. 2008. “Biblioteca de Babel: coleções, dicionários e enciclopédias”. In A leitura e seu público no mundo contemporâneo. Ensaios sobre História Cultural, 129-138. Tradução de Elisa Nazarian. Belo Horizonte: Autêntica Editora.

MOLLIER, Jean-Yves. 2010. 0 dinheiro e as letras. História do Capitalismo Editorial. Tradução de Katia Aily Franco de Camargo. São Paulo: Edusp.

MOLLIER, Jean-Yves. 2008. A leitura e seu público no mundo contemporâneo. Ensaios sobre História Cultural. Belo Horizonte: Autêntica Editora. 
OLIVERO, Isabelle. 1999. L'Invention de la collection. Paris: Institut Mémoires de l'édition contemporaine /Maison des sciences de l'Homme.

PIGLIA, Ricardo. 2014. El último lector. Barcelona: Penguin.

Prefácio Geral da Bibliotheca Universal Antiga e Moderna. 1888. In Viagem à roda do meu quarto, 3-4. Escrito por Xavier de Maistre. Versão de Fernandes Costa. Bibliotheca Universal Antiga e Moderna 1. ${ }^{\mathrm{a}}$ série. Lisboa: Casa Editora David Corazzi.

RIBEIRO, Maria Manuela Tavares. 1999. Livros e Leituras no século XIX. Separata da Revista de História das Ideias, vol. 20. Coimbra: Faculdade de Letras.

SAYÃO, Luis Fernando. 2008-2009. “Afinal, o que é biblioteca digital?”. Revista USP 80 (dez-fev): 6-17. http://www.usp.br/revistausp/80/SUMARIO-80.html.

SANTOS, Maria de Lourdes Lima dos. 1985. “As penas de viver da pena (aspectos do mercado nacional do livro no século XIX)”. Revista Análise Social 21 (86): 187-227.

VAQUINHAS, Irene. 2010. "Perigos da leitura no Feminino. Dos livros proibidos aos aconselhamentos (séculos XIX e XX)”. Revista Ler História 59: 83-99.

VENÂNCIO, Giselle Martins. 2005. Lisboa - Rio de Janeiro - Fortaleza: Os caminhos da coleção Biblioteca do Povo e das Escolas traçados por David Corazzi, Francisco Alves e Gualter Rodrigues. Lisboa: Universidade NOVA de Lisboa.

\section{NOTAS}

1. Como local de guarda e manuseio de material escrito, o conceito é registrado desde 3000 a.C, na Mesopotâmia. Com o inicial sentido de móvel de madeira provido de portas e prateleiras, adquire gradativamente referência topográfica, "até atingir o [sentido] de dependência, divisão com o sinônimo de libraria", no século XIV (Faria e Pericão 2008, 147).

2. Ver ainda: Méndez Rodriguez, Eva Maria. "La Biblioteca Digital como concepto: realidad, utopía e índice de contemporaneidade”. In Rodriguez Ortega, Nuria (coord.). Teoría y literatura artística en la sociedad digital: construcción y aplicabilidad de colecciones textuales informatizadas, 25-44. Gijón: Trea, 2009.

3. São exemplos citados pelo autor coleções como Bibliothèque universelle et historique (1686-1693), Bibliothèques universelle et choisie (1714-1727), Bibliothèque universelle des dames (1785-1797).

4. Eliana Dutra amplia para a paisagem editorial oitocentista não restrita à França, relacionando mais diretamente ao caso do mercado editorial brasileiro (Dutra 2006, 300).

5. Para Portugal, exemplo precursor vocacionado para um público mais amplo, que procurou acasalar problemáticas mais eruditas com conhecimentos práticos, foi 0 Panorama (1837-1868), fundado por Alexandre Herculano com o sintomático subtítulo "jornal litterario e instructivo da Sociedade Propagadora dos Conhecimentos Uteis”. Cf. SILVA, João Lourival da Rocha Oliveira e. 2014. O Panorama (1837-1844): Jornalismo e Ilustração em Portugal na Primeira Metade de Oitocentos. Covilhã: Livros LabCom; CORREIA, Rita. 2012. "O Panorama". In Hemeroteca Digital. [Em rede: http://hemerotecadigital.cm-lisboa.pt/FichasHistoricas/Panorama.pdf].

6. Segundo análise de Luís Miguel Bernardo, o forte movimento de divulgação científica contou com o esforço de cientistas e jornalistas em França, Alemanha, Inglaterra e Estados Unidos desde as primeiras décadas do século XIX e intensificado a partir da segunda metade do Oitocentos (Bernardo, 2013).

7. Entre outros estudos, essa dimensão pode ser vista em Santos, 1985.

8. Cf. Branco, Camilo Castelo. 1867. Cousas leves e pesadas. Porto: Casa de Luiz José d'Oliveira editor. 


\title{
RESUMOS
}

Este artigo busca estabelecer conexões entre os diferentes usos do termo "biblioteca sem muros" em distintos territórios, temporalidades e intencionalidades. Neste percurso, as "bibliotecas sem muros" aparecem em coleções editoriais na França do século XVII, como também formando leitores nos pampas argentinos no século XIX ou voltadas às classes médias portuguesas do Oitocentos. Desse exercício em torno da ideia de "biblioteca sem muros", quer seja como livro, quer seja como coleção, quer seja como prática, discutem-se alguns exemplos demonstrativos em que o "como se lê" e o "o que se lê" podem fundar ou alterar os próprios projetos de bibliotecas.

This article seeks to relate the different uses of the term "library without walls" in distinct territories, temporalities, and intentionalities, such as in editorial collections in 17th century France and in the shaping of readers in the 19th century Argentinian pampas or in the Portuguese middle-class of the 1800s. Based on this idea of "libraries without walls," whether in the form of books, collections, or practices, some demonstrative examples are discussed in which "how to read" or "what to read" may establish or modify actual library projects.

\section{ÍNDICE}

Palavras-chave: bibliotecas, coleções editoriais, leitores, bibliotecas virtuais, história da leitura Keywords: libraries, editorial collections, readers, virtual libraries, history of reading

\author{
AUTOR \\ DÉBORA DIAS \\ CHAM, Faculdade de Ciências Sociais e Humanas, FCSH, Universidade NOVA de Lisboa, 1069-061 \\ Lisboa, Portugal. ORCID iD: https://orcid.org/0000-0003-3216-4344. E-mail: \\ deboradm@gmail.com.
}

